\title{
SOIL MOISTURE CALIBRATION OF TDR MULTILEVEL PROBES
}

\author{
Daniel Serrarens ${ }^{1}$; Jim L. MacIntyre ${ }^{1}$; Jan W. Hopmans ${ }^{1 *}$; Luis H. Bassoi² \\ ${ }^{1}$ Department of Land, Air and Water Resources, Hydrology Program, University of California, Davis, CA: 95616, \\ USA. \\ ${ }^{2}$ Embrapa Semi-Árido, C.P. 23 - CEP: 56300-000 - Petrolina, PE. \\ *Corresponding author<jwhopmans@ucdavis.edu>
}

\begin{abstract}
Time domain reflectometry (TDR) probes are increasingly used for field estimation of soil water content. The objective of this study was to evaluate the accuracy of the multilevel TDR probe under field conditions. For this purpose, eight such TDR probes were installed in small plots that were seeded with beans and sorghum. Data collection from the probes was such that soil moisture readings were automated and logged using a standalone field unit. Neutron probe measurements were used to calibrate the TDR probes. Soil-probe contact and soil compaction were critical to the accuracy of the TDR, especially when a number of TDR probes are combined for a single calibration curve. If each probe is calibrated individually, approximate measurement errors were between 0.005 and $0.015 \mathrm{~m}^{3} \mathrm{~m}^{-3}$. However, measurement errors doubled to approximately 0.025 to $0.03 \mathrm{~m}^{3} \mathrm{~m}^{-3}$, when TDR probes were combined to yield a single calibration curve.

Key words: TDR, soil water content, neutron probe
\end{abstract}

\section{CALIBRAÇÃO DE SONDAS TDR DE NÍVEIS MÚLTIPLOS DE PROFUNDIDADE, PARA UMIDADE DO SOLO}

\begin{abstract}
RESUMO: As sondas TDR (Time Domain Reflectometry) são cada vez mais utilizadas para a estimativa da umidade do solo no campo. Este estudo teve como objetivo avaliar a exatidão das sondas TDR providas de sensores múltiplos para diversas profundidades. Para isso, oito sondas foram instaladas em pequenas parcelas que foram semeadas com feijão e sorgo. A coleta de dados com as sondas foi feita de forma automatizada $e$ armazenada em "data logger". Para calibrar as sondas TDR foi utilizada sonda de neutrons. A exatidão do TDR foi sensível ao contato solo-sonda e à compactação do solo, especialmente quando várias sondas são utilizadas para compor uma única curva de calibração. Quando cada sonda foi calibrada individualmente, os erros de medidas foram da ordem de 0,005 a $0,015 \mathrm{~m}^{3} \mathrm{~m}^{-3}$. Entretanto, os erros dobraram para 0,025 a 0,03 $\mathrm{m}^{3}$ $\mathrm{m}^{-3}$ quando as sondas TDR foram combinadas para produzir uma única curva de calibração.
\end{abstract}

Palavras-chave: TDR, sonda, água do solo, neutron

\section{INTRODUCTION}

The application of time domain reflectometry (TDR) to measure in situ volumetric water content has now been widely accepted. Since its introduction in the early 1980's (Topp et al., 1980), TDR is now among the most utilized soil moisture measurement techniques in both laboratory and field. Advantages of TDR include its small measurement volume, its relative ease of operation, and its ability to be automated and multiplexed, when compared with neutron probe or gravimetric techniques. Moreover, it has been shown that a single calibration curve can be used for most mineral soil types, eliminating the need for soilspecific calibration (Topp et al, 1980). For field estimation of soil water content, TDR and other dielectric techniques are often preferred over neutron probe measurements, due to its automation capabilities and the fact that regulations and special handling requirements that come with the use of radioactive sources are not required. Through TDR multiplexing, unattended and frequent water content measurements can be made with many probes sequentially, thereby allowing the measurement of temporal and spatial soil water content changes.
Two different approaches are generally used for the calibration of TDR probes. These are either empirically-based (Topp et al., 1980; Herkelrath et al., 1991), or the calibration is based on theory and derived from physically based mixing models (De Loor, 1968; Dobson et al., 1985; Dasberg \& Hopmans, 1992; Dirksen \& Dasberg, 1993; Yu et al., 1999).

The development of segmented probes (Hook et al., 1992) allowed for soil water content measurements at more than one depth interval without the need of separate TDR probes for each depth interval. This is especially advantageous in the field where a single probe installation is required for soil moisture measurements at multiple depths. Frueh \& Hopmans (1997) tested a multilevel probe under ideal laboratory conditions. Moreover, they determined that the standard error for the TDR-measured volumetric water content in the field for a uniform coarse gravelly sand was less than $0.03 \mathrm{~m}^{3} \mathrm{~m}^{-3}$, when using the same calibration curve for each of 5 segments of all 10 TDR probes combined. Even better results were obtained if probe-specific calibration curves were used. It was noted that incomplete contact between the TDR probe and the surrounding soil created an air gap, which significantly increased the uncertainty of the TDR measurement. 
Using the calibration model developed by Herkelrath et al. (1991), Hook \& Livingston (1996) derived a physically based calibration equation in which the volumetric water content was linearly related to the travel time of the TDR signal. This approach is simple and physically based. Differences between segments and probes were accounted for by taking into consideration travel time measurements with the probes in air.

The objective of this study was to continue investigations on the accuracy of the segmented, vertical TDR probe ${ }^{2}$, using similar calibration procedures as used in Frueh \& Hopmans (1997). This was done through comparison with neutron probe measurements in an agricultural field for two different crops.

\section{THEORY}

The time domain reflectometry technique (TDR), consists of measuring the travel time of electromagnetic (EM) pulses along two or more wave-guides with known length. This travel time is related to the dielectric constant of the medium in which the wave-guide is inserted (FellnerFeldegg, 1969):

$$
T=\frac{2 L \sqrt{\varepsilon_{a p p}}}{c}
$$

where $T$ is travel time, $L$ is length of the wave-guide (probe), $\varepsilon_{\text {app }}$ is the soil's apparent dielectric constant, and $\mathrm{C}$ is the speed of light in vacuum.

Taking advantage of the wide differences in dielectric constants of the soil-water-air system components $\left(\varepsilon_{\text {water }}=80.4, \varepsilon_{\text {air }}=1\right.$ and $\varepsilon_{\text {soil }}=3-7$ depending on texture and composition), changes in water content modify the dielectric constant of the soil and affects the travel time of the EM wave, permitting an indirect determination of the soil's volumetric water content.

Calibration of conventional TDR probes assumes that each phase of the soil-water-air system contributes independently to the EM wave travel time in bulk soil $\left(T_{b s}\right)$, with a proportional distribution of travel time relative to the volume fraction of each soil phase along the total probe length, L (Hook \& Livingston, 1996), or

$$
\mathrm{T}_{\mathrm{bs}}=\Sigma \mathrm{TT}_{\mathrm{i}}
$$

where i denotes the solid phase (s), water (w) or air (a), and

$$
T_{i}=\frac{2 L_{i} \sqrt{\varepsilon_{i}}}{c}
$$

From $L=\Sigma L_{i}$, it follows that $\frac{L_{i}}{L}=\phi_{i}$, where $\phi_{i}$ denotes the volumetric fraction of phase $i$ in the bulk soil. Consequently,

$$
T_{b s}=\frac{2}{c} \sum L_{i} \sqrt{\varepsilon_{i}}
$$

After dividing $T_{b s}$ (EM travel time in bulk soil) by its value along $L$ in air only $\left(T_{\text {air }}\right)$, the following expression relating travel time and volumetric water content was obtained by Hook and Livingston (1996)

$$
\frac{\mathrm{T}_{b s}}{\mathrm{~T}_{\text {oir }}}=1+\theta\left(\sqrt{\varepsilon_{\mathrm{w}}}-1\right)+\frac{L_{s}}{\zeta}\left(\sqrt{\varepsilon_{s}}-1\right)
$$

where the ratio $L_{s} / L$ is equal to the ratio of soil bulk density $\left(\rho_{\mathrm{b}}\right)$ to soil particle density $\left(\rho_{\mathrm{p}}\right)$. Equation [5] represents a linear relationship between the relative travel time in bulk soil and the volumetric water content. A linear form is assumed to be valid for the multilevel TDR probe as well, despite that this probe type includes solid epoxy material ( $\varepsilon$ is about 3 ) between the waveguides.

The multilevel TDR probe uses diodes, distributed along the parallel wave-guide probe. These diodes control the trajectory of EM wave pulses by either shortening or opening selected probe segments (Hook et al., 1992), so that the EM wave's travel time can be computed for each selected segment of the TDR probe. The diodes of the multilevel probe divide the probe into a total of five segments: two $15-\mathrm{cm}$ long segments $(0-15 \mathrm{~cm}$ and $15-30$ $\mathrm{cm})$ and three $30-\mathrm{cm}$ long segments $(30-60 \mathrm{~cm}, 60-90 \mathrm{~cm}$, and $90-120 \mathrm{~cm})$. The probe consists of two parallel aluminum rods with a solid epoxy material between the rods, resulting in a cross-sectional area of $1.9 \times 1.3 \mathrm{~cm}$. This specific measurement equipment measures and interprets the signal travel times, calculating both travel time (in nanoseconds) and volumetric water content $(\theta)$ using predetermined calibration curves for each segment. However, the presented analysis only uses the calculated travel times, from which calibration curves are determined.

To account for variations in probe geometry between the probes, Hook et al. (1992) recommends calibrating each probe separately from measurements of travel time in both air and water, a procedure followed by Frueh \& Hopmans (1997) as well. However, in this study we eliminated differences in probes solely by dividing the travel time in bulk soil $\left(T_{\text {bs }}\right)$ by $T_{\text {air }}$. Frueh \& Hopmans (1997) concluded that multilevel TDR probes may be calibrated from limited calibration data, as is usually done for neutron probe calibration. They found that when ensuring soil-probe contact, standard error values were as low as 0.015 $\mathrm{m}^{3} \mathrm{~m}^{-3}$ with $R^{2}$-values larger than 0.80 . The objective of this study was the reevaluate the accuracy of the multilevel

\footnotetext{
${ }^{2}$ ESI Environmental Sensors Inc. 100-4243 Glanford Avenue, Victoria, B.C. V8Z4B9, Canada. Reference to specific products does not imply endorsement by the authors.
} 
TDR probe for a different soil type, when combining TDR segments and probes into a single calibration curve.

\section{MATERIAL AND METHODS}

Each of the five segments of 8 multilevel TDR probes (MP-917) was tested by measurement of EM travel time in both air $\left(\mathrm{T}_{\text {air }}\right)$ and water $\left(\mathrm{T}_{\text {water }}\right)$. Travel times were collected in triplicate. This was done for coaxial cable lengths of 3, 10, and $27 \mathrm{~m}$ between the TDR probe and multiplexer (Campbell Model SDMX50 with AM416). The travel time data showed little effect of cable length on measured travel times along the probes (data are not shown). Travel times were stored in a Campbell datalogger (Model CR-10), while electrical power was supplied by a solar panel and a $12 \mathrm{~V}$ battery.

The field experiment was carried out at Campbell Tract, an experimental field research facility at the University of California, on the Davis campus. The soil is a Yolo silty clay loam, with an approximate clay content of $21 \%$ (Hopmans et al., 1990). The mean and standard deviation of the dry soil bulk density, as determined from 3 sets of density samples ( 13 cores per depth increment) are shown in Figure 1. As was also shown by Hopmans et al. (1990), soil bulk density generally decreased with depth, but slightly increased at about $90 \mathrm{~cm}$ depth because of the presence of a $5-10 \mathrm{~cm}$ sand layer. The experimental plot was partly seeded in sorghum (Sorghum bicolor L., sites 1 and 2) and bean (Phaseolus vulgaris L., site 3) on Julian date 170 (June 19). Three TDR multilevel probes were installed at sites 1 and 3 , and two at site 2, with probes at each site approximately $1 \mathrm{~m}$ apart. The three experimental plots were within $20 \mathrm{~m}$ of each other. Before installing the $1.9 \times 1.3-\mathrm{cm}$ probes, pilot holes were created with a $1.3-\mathrm{cm}$ diameter steel rod to facilitate insertion of TDR probes and to ensure good soil-probe contact.

Neutron probe access tubes were installed at about $0.3 \mathrm{~m}$ distance from each TDR probe. While installing the neutron probe access tubes, $60 \mathrm{~cm}^{3}$ soil samples were collected at $15 \mathrm{~cm}$ depth increments up to a depth of $1.05 \mathrm{~m}$, corresponding to the depths at which neutron probe readings were obtained. Additional soil cores were collected from $8.2-\mathrm{cm}$ diameter $\times 6.0-\mathrm{cm}$ length brass rings at selected times during the growing season. This permitted calculation of the average soil bulk density per depth increment (Figure 1). In addition, during the growing season and using these bulk density values, gravimetric soil samples were taken at the same $15-\mathrm{cm}$ depth increments for neutron probe calibration. A total of 100 such samples were collected to calibrate the neutron probe over a wide range of soil water content values.

The plot was cultivated once for weed control and irrigated three times during the season. Approximate irrigation depths were $75 \mathrm{~mm}$ (beans on Julian date 197), $75 \mathrm{~mm}$ (sorghum on Julian date 205), $50 \mathrm{~mm}$ (both crops on Julian date 219) and $50 \mathrm{~mm}$ (both crops on Julian date 232). The TDR system was programmed to collect triplicate

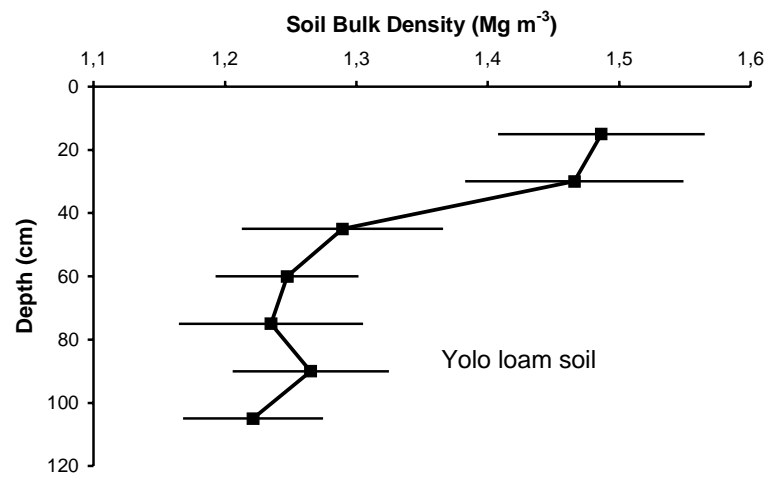

Figure 1 - Depth distribution of dry bulk density.

readings every two hours during the growing season. Neutron probe readings were collected 3 times weekly early in the season and biweekly at the end of the season resulting in a total of 45 neutron probe measurements at every depth for each location. The neutron probe measurements were used to calibrate the TDR probes, using linear regression of volumetric water content versus travel times (Eq. [5]) at corresponding measurement times. Total rainfall during the growing season (Julian date 197 315) was approximately $47 \mathrm{~mm}$.

There were various reasons why we calibrated the TDR probes using neutron probe readings instead of gravimetric sampling. First, once a calibration curve of the neutron probe is obtained, TDR calibration points were easily obtained from simultaneous TDR and neutron probe measurements. Second, continued calibration of the TDR probes during the growing season would create significant soil disturbance near the TDR probes, if gravimetric sampling were used. Third, since the neutron probe measurement volume is much larger than sample volumes generally used for gravimetric sampling, the data scatter of the TDR-neutron probe calibration curves is less than if TDR were calibrated using gravimetric sampling.

\section{RESULTS AND DISCUSSION}

Although Frueh \& Hopmans (1997) recommended inclusion of TDR probe geometry parameters in their TDR calibration, corrections were needed because of differences between probe geometry and segment lengths. Corrections were incorporated in the calibration by simply dividing bulk soil travel time by the travel time in air $\left(\mathrm{T}_{\text {air }}\right)$, as in Equation [5] or in water $\left(T_{\text {water }}\right)$. As is intuitively clear from Eq. [3], $T_{\text {air }}$-values varied approximately linearly with segment length, and ranged from 1.5 (15-cm segments) to 3.5 nanoseconds (30-cm segments), whereas $T_{\text {water }}$ values ranged between 6 and 14 nanoseconds, respectively. The coefficients of variation between probes deviated between 0.5 and $1.0 \%$ among segments. The $R^{2}$-values of the linear calibration equations (division of $T_{b s}$ by $T_{\text {air }}$ ) were as high 
or higher than corrected travel times using additional probespecific calibration parameters as was done by Frueh \& Hopmans (1997). Hence, all TDR data presented and analyzed have been normalized relative to $T_{\text {air }}$.

The neutron probe calibration data are presented in Figure 2. From visual inspection of depth-specific calibration curves, it was decided to combine the values for $15 \mathrm{~cm}$ and $30 \mathrm{~cm}$ depth, and separately combine the $45,60,90$ and $105 \mathrm{~cm}$ calibration data to obtain two calibration curves for the near soil surface $(0-30 \mathrm{~cm})$ and subsurface $(30-120 \mathrm{~cm})$, respectively. We encountered larger uncertainty in the data than usual, specifically for the $0-30 \mathrm{~cm}$ depth interval, which we suggest is caused by local soil water content variations caused by root water uptake. Values for correlation coefficients were 0.59 and 0.81 for the $0-30 \mathrm{~cm}$ and $30-120 \mathrm{~cm}$ depth interval, respectively. These calibration curves were subsequently used for the TDR calibration. Hence, volumetric water content values estimated from the neutron probe readings were linearly related with TDR normalized travel time. This calibration procedure was followed so that calibration over a wide range of water content values was obtained without successive destructive soil sampling from gravimetric measurements near the TDR probes.

To match simultaneous TDR with neutron probe readings, a specific averaging procedure was applied for the $0-30 \mathrm{~cm}$ depth interval. First, TDR readings for the 0 15 and $15-30 \mathrm{~cm}$ segment were combined to yield an average travel time for the $0-30 \mathrm{~cm}$ depth. Second, this average reading was matched with a weighted average neutron probe water content, using both the $15 \mathrm{~cm}(66.6 \%)$ and $30 \mathrm{~cm}(33.4 \%)$ measurements. The $30-60$ and $60-90$ $\mathrm{cm}$ TDR segments were matched with weighted average neutron probe readings using three depths. For example, travel time of the $30-60 \mathrm{~cm}$ TDR segment was paired with neutron probe readings at 30,45 , and $60 \mathrm{~cm}$ depths, with $50 \%$ weight attributed to the water content of the $45 \mathrm{~cm}$ depth measurements and $25 \%$ weight to the 30 and $60 \mathrm{~cm}$ neutron probe readings. Finally, the $90-120 \mathrm{~cm}$ TDR

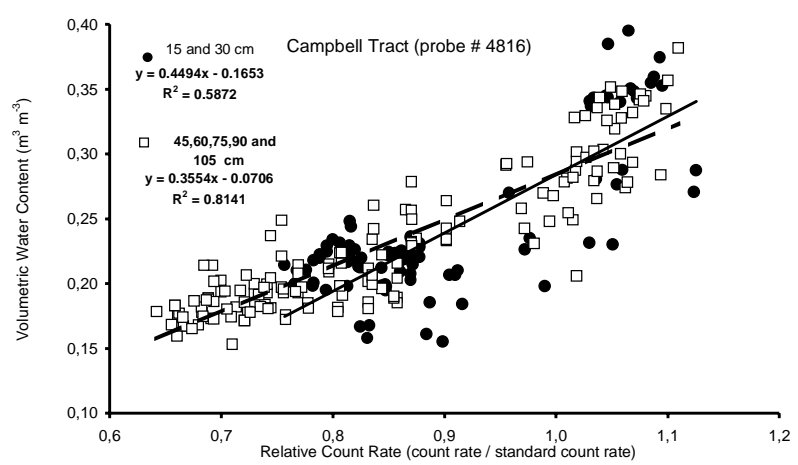

Figure 2 - Neutron probe calibration for TDR monitoring sites. Solid line and dots represent the 15 and $30 \mathrm{~cm}$ calibration data, and the dashed line and open squares represent the 45 , $60,75,90$, and $105 \mathrm{~cm}$ depth calibration data. segment was matched with a weighted average of the 90 $(33.4 \%)$ and $105 \mathrm{~cm}(66.6 \%)$ neutron probe measurements.

Segment-specific calibration curves for the $60-90$ segment for all 8 TDR probes are presented in Figure 3. Although $\mathrm{R}^{2}$-values for each specific segment were high, and varied between 0.80 and 0.95 , variations between TDR probes were also large. For example, data represented by triangles belong to a TDR probe installed in the sorghum plot, whereas the solid diamonds represent calibration data of another $60-90 \mathrm{~cm}$ segment of a TDR probe in the bean plot. Segment-specific calibrations yielded measurement errors in the range of 0.005 to $0.015 \mathrm{~m}^{3} \mathrm{~m}^{-3}$, and they were of about equal magnitude as expected of neutron probe measurements. Differences in calibration between segments were likely caused by incomplete soil-probe contact. Air gaps led to smaller travel times (dielectric constant of air is much smaller than soil), especially when the soil was wet. Consequently, the slope of the calibration line was steeper as soil probe contact diminished, whereas the intercept of the linear curve tends not to be affected. In either case, calibration lines appear to be linear, as predicted from Eq. [5].

When combining all TDR probes, segment specific $R^{2}$ values ranged from 0.40 to 0.62 . Without much loss of predictability, TDR calibration data for the 0-30, 3060 and $60-90 \mathrm{~cm}$ segments could be combined to yield a single calibration curve for the $0-90 \mathrm{~cm}$ soil depth (Figure 4). The goodness of fit for the predicted volumetric water content, as computed from the root mean squared error (RMSE)

$$
R M S E=\sqrt{\frac{1}{\mathrm{~N}} \Sigma\left(\theta_{n p}-\theta_{c a l}\right)^{2}}
$$

were equal to 0.028 and $0.026 \mathrm{~m}^{3} \mathrm{~m}^{-3}$ for the $0-90$ and 90 $120 \mathrm{~cm}$ depth increment, respectively.

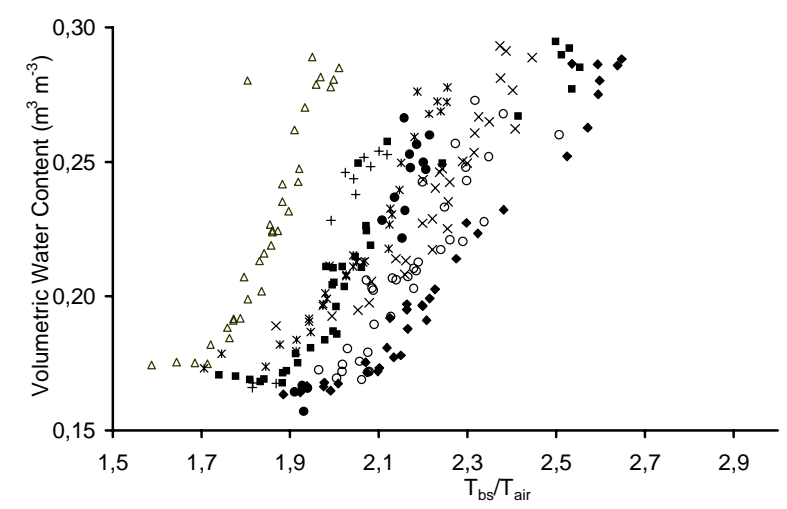

Figure 3 - TDR calibration curves for the $60-90 \mathrm{~cm}$ segment for all TDR probes combined. 


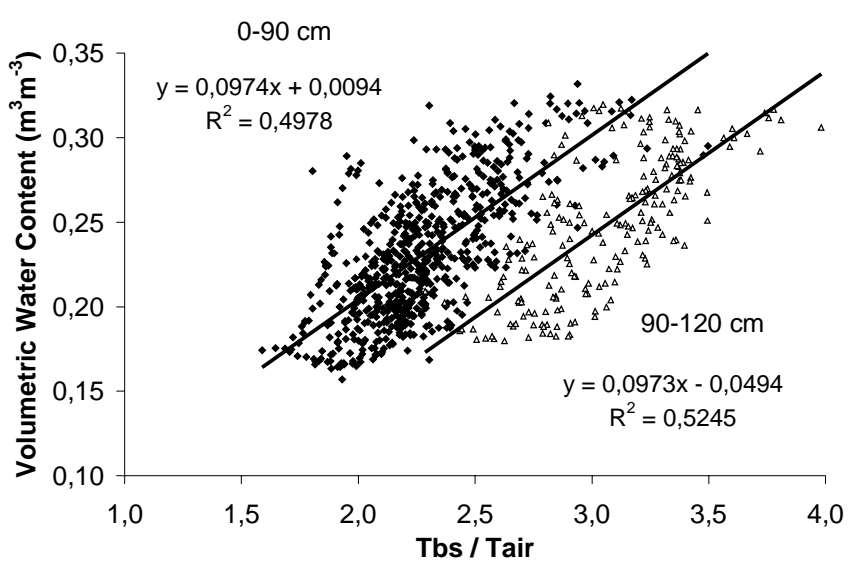

Figure 4 - Calibration curves for the TDR combining all segments and probes for the $0-90 \mathrm{~cm}$ and $90-120 \mathrm{~cm}$ depth.

The distinct calibration curve for the $90-120 \mathrm{~cm}$ segment was interesting, since differences in travel time between the $30-\mathrm{cm}$ segments were not apparent for the measurements in either air or water. We conclude that the longer travel times in field soil for the $90-120 \mathrm{~cm}$ depth segments was caused by soil compaction. Severe soil compaction for the bottom segment was expected as soil collapsed and dropped to the bottom as the TDR probe was inserted through the pilot hole. Increased soil densities have shown to increase the bulk soil dielectric constant (Dirksen \& Dasberg, 1993) and bulk soil travel time, thereby shifting the calibration curve (Figure 4). In contrast, Rothe et al. 1997), measured a decrease of bulk soil dielectric constant after TDR probe installation. They attributed this decrease in the soil dielectric to the reduced porosity as caused by the elimination of the largest waterfilled pores by compaction. It is expected that the effect of compaction on the bulk soil dielectric is largely controlled by the degree of soil saturation at the time of compaction.

Finally, Figure 5 presents soil water storage changes $(\mathrm{cm})$ for the (a) beans and (b) sorghum plots between Julian dates 195 and 318. These data included three irrigation events $(5$ and $7 \mathrm{~cm}$ ) and several small rainfall events $(0-1.5 \mathrm{~cm})$ at the end of the growing season. These results clearly showed that soil water storage measured with TDR was responsive to irrigation and rainfall events.

Further analysis of TDR data confirmed that TDR field calibration was mostly affected by probe installation. Consequently, variation in calibration lines for TDR probes was mostly caused by differences in soil-probe contact and soil compaction of the surrounding soil, and much less by their individual makeup and geometry. For example, while combining equal-depth segments for all probes, differences between calibration curves were hardly affected by using normalized bulk soil travel times as was done in Figures 3,4 , and 5 .
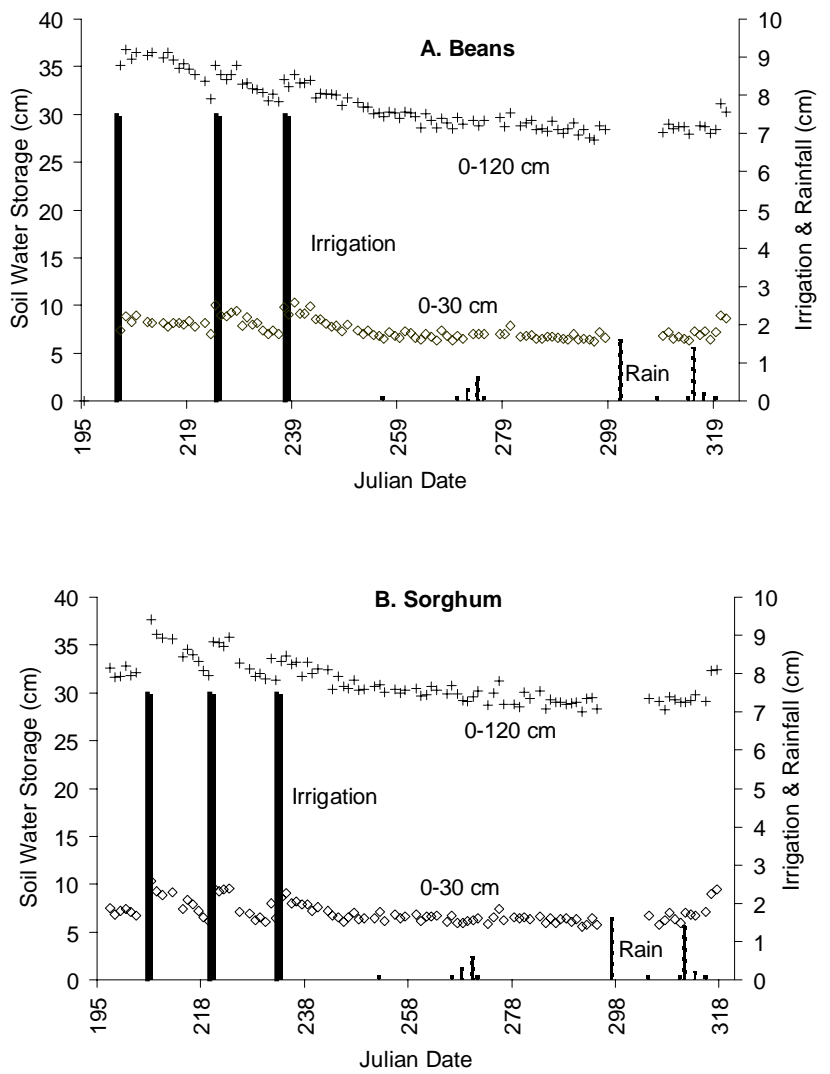

Figure 5 - Soil water storage $(\mathrm{cm})$ for the $0-30 \mathrm{~cm}$ and the $0-120 \mathrm{~cm}$ depths using the calibration curves of Figure 4 , as a function of time (Julian Date) and their response to irrigation and rainfall $(\mathrm{cm})$.

\section{CONCLUSIONS}

The accuracy of TDR measurements was largely controlled by proper probe installation, specifically influenced by the degree of physical contact between TDR probes and the surrounding soil, and soil compaction. Incomplete soil-probe contact and air gaps reduced TDR readings, whereas alternative installation procedures must be designed to minimize soil compaction. Nevertheless, even with incomplete soil-probe contact, excellent calibration results were obtained when each probe was calibrated separately, yielding measurement errors between 0.005 and $0.015 \mathrm{~m}^{3} \mathrm{~m}^{-3}$. When TDR probes were combined to yield a single calibration curve, measurement errors were estimated to be in the range of 0.025 to $0.03 \mathrm{~m}^{3} \mathrm{~m}^{-3}$.

\section{REFERENCES}

DASBERG, S.; HOPMANS, J.W. Time domain reflectometry calibration for uniformly wetted sandy and clayey soils. Soil Science Society of America Journal, v.49, p.293-297, 1992.

DE LOOR, G.P. Dielectric properties of heterogeneous mixtures containing water. Journal Microwave Power, v.3-2, p.67-73, 1968. 
DIRKSEN, C.; DASBERG, S. Improved calibration of time domain reflectometry soil water measurements. Soil Science Society of America Journal, v.57, p.660-667, 1993.

DOBSON, M.C.; ULABY, F.T.; HALLIKAINEN, M.T.; EL-RAYES M.A. Microwave dielectric behavior of wet soil. II: Dielectric missing models. IEEE Transactions Geosciences Remote Sensing GE, v.23, p.35-46, 1985.

FELLNER-FELDEGG, $\mathrm{H}$. The measurement of dielectrics in the time domain. Journal of Physics and Chemistry, v.73, p.616-623, 1969.

FRUEH, W.T.; HOPMANS, J.W. Soil moisture calibration of a TDR multilevel probe in gravely soils. Soil Science, v.162, p.554-565, 1997.

HERKELRATH, W.N.; HAMBURG, S.P.; F. MURPHY. Automatic, real-time monitoring of soil moisture in a remote field area with time domain reflectometry. Water Resources Research, v.27, p.857-864, 1991.

HOOK, W.R.; LIVINGSTON, N.J. 1996. Errors in converting time domain reflectometry measurements of propagation velocity to estimates of soil moisture content. Soil Science Society of America Journal, v.60, p.35-41, 1996.
HOOK, W.R.; LIVINGSTON, N.J.; SUN, Z.R.; HOOK, P.B. Remote diode shorting improves measurement of soil water by time domain reflectometry. Soil Science Society of America Journal, v.56, p.1384-1391, 1992.

HOPMANS, J.W.; MACINTYRE, J.; SOUTHARD, R.J. Water quality and subsurface soil variabilities affect infiltration. California Agriculture, v.44, p.10-12, 1990.

ROTHE, A., WEIS, W.; KREUTZER, K.; MATTHIES, D.; HESS, U.; ANSORGE, B. Changes in soil structure caused by the installation of time domain reflectometry probes and heir influence on the measurement of soil moisture. Water Resources Research, v. 33, p.1585-1593, 1997

TOPP, G.C.; DAVIS, J.L ; ANNAN, A.P. Eletromagnetic determination of soil water content: measurements in coaxial transmission lines. Water Resources Research, v.16, p.574-582, 1980.

YU, C.; WARRICK, A.W.; CONCLIN, M.H. Derived functions of time domain reflectometry for soil moisture measurement. Water Resources Research, v.35, p.1789-1796, 1999.

Received July 26, 1999 